\title{
HUBUNGAN STATUS EKONOMI DAN PANDANGAN POSISI ANAK DENGAN SIKAP ORANG TUA TERHADAP KEKERASAN PADA ANAK
}

\author{
Ati Nurwita* Elzza Nurfitriani**Sri Yuniarti***
}

\begin{abstract}
ABSTRAK
Keluarga merupakan lini terdepan untuk membentuk anak-anak yang berkualitas melalui pemberian pola asuh yang tepat. Terdapat beberapa fenomena dalam keluarga untuk menerapkan kedisiplinan pada anak yaitu dengan kekerasan. Data Komisi Perlindungan Anak Indonesia (KPAI) tahun 2014, terdapat 93 kasus kekerasan pada anak, 13\% pelakunya adalah keluarga. Faktor penyebab orang tua melakukan kekerasan pada anak diantaranya kemiskinan dan pandangan keliru tentang posisi anak dalam keluarga. Tujuan penelitian untuk menganalisis Hubungan Status Ekonomi Dan Pandangan terhadap Posisi Anak Dengan Sikap Orang Tua Terhadap Kekerasan Pada Anak. Jenis penelitian analitik, desain cross sectional. Responden penelitian sebanyak 73 ibu di Kampung Cidahu Kecamatan Ngamprah Kabupaten Bandung Barat. Data yang dikumpulkan data primer, dengan kuesioner dan lembar ceklist. Analisis univariat dan bivariat. Hasil penelitian didapatkan dari 73 responden sebagian besar $(94,5 \%)$ dari responden status ekonomi menengah kebawah, sebagian besar $(53,4 \%)$ memiliki pandangan tidak keliru tentang posisi anak dalam keluarga dan setengahnya $(47,9 \%)$ memiliki sikap positif terhadap kekerasan pada anak. Uji bivariat status ekonomi dengan sikap didapatkan nilai $\mathrm{p}=0,616(\mathrm{p}>\alpha)$ dan pandangan posisi anak dengan sikap ibu didapatkan nilai $\mathrm{p}=0,743(\mathrm{p}>\alpha)$. Hal ini menunjukkan $\mathrm{H}_{0}$ gagal ditolak yang berarti tidak ada hubungan status ekonomi keluarga dan pandangan terhadap posisi anak dengan sikap ibu terhadap kekerasan pada anak.
\end{abstract}

Kata Kunci: Kekerasan pada anak, Status ekonomi, Posisi anak

\begin{abstract}
The family is the leading line for shaping quality children with the provision of parenting. There are several phenomena in the family to apply discipline to children by child abuse. Data from KPAI at 2014 there 93 child abuse cases and $13 \%$ the perpetrators is families. Factors the cause parent make child abuse such as economic state and value of child in families. This research to analys the relationship economic status and value of the child in families with mother's attitude about child abuse. The research is analytic with cross sectional design. The subjects were 73 mothers, live in Cidahu Villages, Ngamprah District, Bandung Barat. The Collect data is primer with questionnaireand checklist. Analys of data with univariate and bivariate. Obtained from 73 respondences: there $94,4 \%$ of midle and lower economic status, there $53,4 \%$ had a true value of child, and $47,9 \%$ respondences have a positive attitude about child abuse. The bivariate analysis for economic status with attitude obtained $p$ value $=0,616(p>a)$ and the value of child with attitude obtained $p$ value $=0,743(p>$ 0 ). This indicates that $\mathrm{H}_{0}$ fails to be rejected, which means that there is no relationship between the family's economic status and the value of the child with the mother's attitude about child abuse.
\end{abstract}

Keyword: Child abuse, Economic status, value of the child

*,**,*** Staf Pengajar D3 Kebidanan STIKes Jenderal A. Yani Cimahi 


\section{PENDAHULUAN}

Anak merupakan generasi penerus bangsa. Anak-anak yang berkualitas dapat menjamin kemajuan bangsa pada masa yang akan datang. Untuk melahirkan anak-anak yang berkualitas dinilai dari aspek sehat secara fisik, mental, emosional dan sosial. Keluarga merupakan lini terdepan untuk membentuk anak-anak yang berkualitas melalui pemberian pola asuh yang tepat. ${ }^{1}$

Namun demikian, keluarga sering memperlakukan salah pada anak. Dengan dalih untuk menjaga kedisiplinan pada anak, sering sekali pola asuh yang diterapkan adalah dengan kekerasan. ${ }^{1}$ Pemahaman yang bias mengenai konsep disiplin memiliki efek yang besar terhadap perkembangan anak. Jika anak tumbuh dan berkembang di keluarga dengan menerapkan konsep disiplin yang salah maka akan salah pula cara pendisiplinannya. Hal tersebut tidak menutup kemungkinan terjadinya praktek kekerasan. ${ }^{2}$

Data Komisi Perlindungan Anak Indonesia (KPAI) tahun 2014, terdapat 93 kasus kekerasan pada anak, $13 \%$ pelakunya adalah keluarga. ${ }^{3}$ Kekerasan yang terjadi di lingkungan keluarga terjadi karena banyak orang tua yang menganggap kekerasan pada anak adalah hal yang wajar. ${ }^{4}$ Orang tua menganggap bahwa anak adalah seseorang yang tidak tahu apa-apa dan bagian dari pola asuh untuk mendidik anak menjadi disiplin. ${ }^{2}$

Disamping itu, kekerasan pada anak di lingkungan keluarga terjadi dikarenakan riwayat orang tua yang dulunya dibesarkan dalam kekerasan sehingga cenderung meniru pola asuh yang telah mereka dapatkan sebelumnya. Stress, kemiskinan, isolasi sosial, lingkungan yang mengalami krisis ekonomi, tidak bekerja, pandangan keliru tentang posisi anak dalam keluarga serta minimnya pengetahuan agama orang tua yang turut berperan menjadi penyebab orang tua melakukan kekerasan pada anaknya. ${ }^{1,2,4}$

Berdasarkan laporan yang diperoleh dari Kepolisian Resort (Polres) Kota Cimahi didapatkan data kasus kekerasan pada anak yang tersebar di 9 kecamatan Kabupaten Bandung Barat pada tahun 2014 sampai bulan Oktober 2016 seperti berikut :

Tabel 1. Kasus Kekerasan yang Terjadi pada Anak di Kabupaten Bandung Barat

\begin{tabular}{lcccccc}
\hline \multirow{2}{*}{ Kecamatan } & \multicolumn{2}{c}{2014} & \multicolumn{2}{c}{2015} & \multicolumn{2}{c}{2016} \\
\cline { 2 - 7 } & $\begin{array}{c}\text { Jumlah } \\
\text { Kasus }\end{array}$ & \% kasus & $\begin{array}{c}\text { Jumlah } \\
\text { Kasus }\end{array}$ & \% kasus & $\begin{array}{c}\text { Jumlah } \\
\text { Kasus }\end{array}$ & kasus \\
\hline Batujajar & 2 & 11.76 & 1 & 5.56 & 1 & 5.27 \\
Cihampelas & 2 & 11.76 & 2 & 11.11 & 1 & 5.27 \\
Cililin & 2 & 11.76 & 2 & 11.11 & 1 & 5.27 \\
Cipatat & 1 & 5.88 & 1 & 5.56 & 2 & 10.5 \\
Cisarua & 2 & 11.76 & 3 & 16.67 & 3 & 15.79 \\
Lembang & 2 & 11.76 & 2 & 11.11 & 1 & 5.27 \\
Ngamprah & $\mathbf{3}$ & $\mathbf{1 7 . 6 5}$ & $\mathbf{2}$ & $\mathbf{1 1 . 1 1}$ & $\mathbf{4}$ & $\mathbf{2 1 . 0 5}$ \\
Padalarang & 2 & 11.76 & 4 & 22.22 & 3 & 15.79 \\
Parompong & 1 & 5.88 & 1 & 5.56 & 3 & 15.79 \\
Total & 17 & 100 & 18 & 100 & 19 & 100 \\
\hline Sumyyyyyyyy
\end{tabular}

Sumber : POLRES Cimahi, 2016

Berdasarkan data tersebut diperoleh kejadian kekerasan pada anak di Kecamatan Ngamprah terbesar di tahun 2016 dengan kenaikan presentase 9,94\% dari tahun sebelumnya. Berdasarkan data dari Polres Kota Cimahi, kejadian kekerasan pada anak, pelakunya dalam lingkungan keluarga tindakan yang terjadi berupa kekerasan fisik.

Dengan tingginya angka kejadian kekerasan dalam lingkungan keluarga, dapat dikaji berawal dari sikap yang ditunjukkan oleh orang tua terhadap kekerasan terhadap anak. Untuk itu tujuan penelitian ini adalah untuk menganalisis Hubungan Status Ekonomi Dan Pandangan terhadap Posisi Anak Dengan Sikap Orang Tua Terhadap Kekerasan Pada Anak 


\section{METODE PENELITIAN}

Penelitian ini adalah penelitian analitik dengan pendekatan cross sectional. ${ }^{5,6}$ Populasi pada penelitian ini adalah ibu yang memiliki anak usia 6-12 tahun Di Kampung Cidahu Kecamatan Ngamprah Bandung Barat, pada bulan Pebruari 2017 yaitu sebanyak 73 responden. Teknik pengambilan sampel total sampling. ${ }^{7}$

Data yang dikumpulkan adalah data primer yang dikumpulkan dengan instrumen kuesioner dan lembar ceklist. ${ }^{6}$ Analisis data dilakukan univariat dan bivariat. Analisis bivariat dengan uji chi square. Dasar pengambilan hipotesis penelitian berdasarkan tingkat signifikansi (nilai $\mathrm{p}$ ), yaitu : Jika $\mathrm{p} \leq 0,05$ maka hipotesis penelitian (Ho) ditolak dan jika $\mathrm{p}>$ 0,05 maka hipotesis penelitian (Ho) diterima. Untuk uji bivariat variabel status ekonomi dengan sikap terhadap kekerasan pada anak dikarenakan tidak memenuhi syarat untuk uji chi square maka digunakan uji fisher sedangkan untuk variabel pandangan terhadap posisi anak dengan sikap terhadap kekerasan pada anak karena syarat terpenuhi maka dilakukan uji chi square. $^{8}$

\section{HASIL PENELITIAN}

Penelitian dilakukan selama bulan Pebruari 2017, data dikumpulkan dengan mendatangi responden dari rumah ke rumah. Data dikumpulkan dengan alat ukur yang telah disiapkan dan telah dilakukan uji validitas dan reliabilitas.

Berikut adalah data yang terkumpul setelah dilakukan analisis univariat dan bivariat, sebagai berikut:

Tabel 2. Distribusi Frekuensi Status Ekonomi, Pandangan terhadap Posisi Anak, dan Sikap terhadap Kekerasan di Kampung Cidahu Kecamatan Ngamprah Kabupaten Bandung Barat 2017

\begin{tabular}{|c|c|c|}
\hline Variabel & Frekuensi & Presentase $(\%)$ \\
\hline \multicolumn{3}{|c|}{ Status ekonomi } \\
\hline Menengah Kebawah & 69 & 94,5 \\
\hline Menengah Keatas & 4 & 5,5 \\
\hline Jumlah & 73 & 100 \\
\hline \multicolumn{3}{|c|}{ Pandangan posisi anak } \\
\hline Tidak keliru & 39 & 53,4 \\
\hline Keliru & 34 & 46,6 \\
\hline Jumlah & 73 & 100 \\
\hline \multicolumn{3}{|c|}{ Sikap terhadap kekerasan } \\
\hline Positif & 35 & 47.9 \\
\hline Negatif & 38 & 52.1 \\
\hline Jumlah & 73 & 100 \\
\hline
\end{tabular}

Berdasarkan tabel 2 didapatkan hasil bahwa dari 73 responden sebagian besar dari responden status ekonomi menengah ke bawah sebanyak 69 orang (94,5\%), sebagian besar memiliki pandangan tidak keliru tentang posisi anak dalam keluarga yaitu sebanyak 39 orang $(53,4 \%)$ dan setengahnya memiliki sikap positif terhadap kekerasan pada anak sebanyak 35 orang $(47,9 \%)$. 
Tabel 3. Hubungan Status Ekonomi Keluarga dengan Sikap Ibu terhadap Kekerasan pada Anak di Kampung Cidahu Kecamatan Ngamprah Kabupaten Bandung Barat Tahun 2017

\begin{tabular}{|c|c|c|c|c|c|c|c|}
\hline \multirow{3}{*}{ Status Ekonomi } & \multicolumn{4}{|c|}{ Sikap } & \multirow{2}{*}{\multicolumn{2}{|c|}{ Jumlah }} & \multirow{3}{*}{$\mathrm{p}$ value } \\
\hline & \multicolumn{2}{|c|}{ Positif } & \multicolumn{2}{|c|}{ Negatif } & & & \\
\hline & $\mathrm{n}$ & $\%$ & $\mathrm{n}$ & $\%$ & $\mathrm{n}$ & $\%$ & \\
\hline & 34 & 49,3 & 35 & 50,7 & 69 & 100 & \\
\hline Menengah kebawah & & & & & & & 0696 \\
\hline Menengah keatas & 1 & 25,0 & 3 & 75,0 & 4 & 100 & 0,010 \\
\hline Jumlah & 35 & 47,9 & 38 & 52,1 & 73 & 100 & \\
\hline
\end{tabular}

Berdasarkan tabel 3 didapatkan hasil bahwa dari 69 responden dengan status ekonomi menengah kebawah dan memiliki sikap positif terhadap kekerasan pada anak sebanyak 34 orang (49,3\%). Hasil uji statistik menggunakan uji fisher dengan $\alpha=0,05$ didapatkan nilai $\mathrm{p}=0,616(\mathrm{p}>\alpha)$. Hal ini berarti $\mathrm{H}_{0}$ gagal ditolak yang berarti tidak ada hubungan status ekonomi keluarga dengan sikap ibu terhadap kekerasan pada anak.

Tabel 4. Hubungan Pandangan terhadap Posisi Anak dengan Sikap Ibu terhadap Kekerasan pada Anak di Kampung Cidahu Kecamatan Ngamprah Kabupaten Bandung Barat Tahun 2017

\begin{tabular}{|c|c|c|c|c|c|c|c|}
\hline \multirow{3}{*}{ Pandangan posisi anak } & \multicolumn{4}{|c|}{ Sikap } & \multicolumn{2}{|c|}{ Total } & \multirow{3}{*}{$\mathrm{p}$ value } \\
\hline & \multicolumn{2}{|c|}{ Positif } & \multicolumn{2}{|c|}{ Negatif } & & & \\
\hline & $\mathrm{n}$ & $\%$ & $\mathrm{n}$ & $\%$ & $\mathrm{n}$ & $\%$ & \\
\hline & 18 & 46,2 & 21 & 53,8 & 39 & 100 & \\
\hline Tidak Keliru & & & & & & & 0,743 \\
\hline Keliru & 17 & 50 & 17 & 50 & 34 & 100 & \\
\hline Jumlah & 35 & 47,9 & 38 & 52,1 & 73 & 100 & \\
\hline
\end{tabular}

Berdasarkan tabel 4 didapatkan hasil bahwa dari 39 responden yang mempunyai pandangan tidak keliru terhadap posisi anak memiliki sikap positif terhadap kekerasan pada anak yaitu sebanyak 18 orang $(46,2 \%)$. Hasil uji statistik menggunakan uji chi square dengan $\alpha=0,05$ didapatkan nilai $\mathrm{p}=0,743(\mathrm{p}>\alpha)$. Hal ini berarti $\mathrm{H}_{0}$ gagal ditolak yang berarti tidak ada hubungan pandangan terhadap posisi anak dengan sikap ibu terhadap kekerasan pada anak.

\section{PEMBAHASAN}

Berdasarkan tabel 2 diketahui bahwa dari 73 responden sebagian besar dari responden status ekonomi menengah kebawah sebanyak 69 orang $(94,5 \%)$, sebagian besar memiliki pandangan tidak keliru tentang posisi anak dalam keluarga yaitu sebanyak 39 orang $(53,4 \%)$ dan setengahnya memiliki sikap positif terhadap kekerasan pada anak sebanyak 35 orang $(47,9 \%)$.

Hasil pengamatan peneliti dilapangan menunjukkan sebagian besar berpendidikan menengah dan belum pernah mendapatkan informasi kekerasan pada anak. Sedangkan pekerjaan ibu rata-rata ibu rumah tangga dengan penghasilan kepala keluarga yang tidak menetap dan pola asuh yang diterapkan didapatkan secara turun temurun.

Pembentukan sikap seseorang dapat dipengeruhi oleh pendidikan. Pendidikan membentuk pola pengetahuan seseorang yang menjadi dasar seseorang untuk bersikap. 
Belum adanya sosialisasi mengenai bentuk kekerasan pada anak dapat membentuk sikap ibu yang mendukung kearah kekerasan pada anak. Sumber informasi merupakan salah satu wadah informasi bagi publik atau masyarakat yang sangat mempengaruhi tanggapan mereka terhadap sesuatu. ${ }^{9}$

Faktor-faktor yang mempengaruhi sikap adalah faktor pengalaman pribadi, kebudayaan, pengaruh orang lain yang dianggap penting, media sosial, lembaga sosial dan faktor emosional. Sikap merupakan reaksi atau respon yang masih tertutup dari seseorang terhadap suatu stimulasi atau objek. Sikap secara nyata menunjukan konotasi adanya kesesuaian reaksi terhadap stimulasi tertentu yang dalam kehidupan sehari-hari merupakan reaksi yang bersifat emosional terhadap stimulasi. Sikap belum merupakan suatu tindakan atau aktivitas, akan tetapi merupakan predisposisi tindakan suatu perilaku. Sikap itu masih merupakan reaksi tertutup, bukan merupakan reaksi terbuka atau tingkah laku yang terbuka. Sikap merupakan kesiapan untuk bereaksi terhadap objek dilingkungan tertentu sebagai suatu penghayatan terhadap objek. ${ }^{9}$

Faktor lain yang memengaruhi sikap seseorang adalah kondisi sosial ekonomi. Kemiskinan yang dihadapi sebuah keluarga sering membawa keluarga tersebut pada situasi kekecewaan yang pada gilirannya menimbulkan kekerasan. Hal ini biasanya terjadi pada keluarga-keluarga dengan anggota yang sangat besar. Masalah keuangan keluarga yang memprihatinkan atau kondisi keterbatasan ekonomi dapat menciptakan berbagai macam masalah sehingga secara relative dapat mempengaruhi jiwa dan tekanan yang sering kali akhirnya dilampiaskan terhadap anak. ${ }^{9,10}$

Pada tabel 3 dan 4 diketahui bahwa $\mathrm{H}_{0}$ gagal ditolak yang berarti tidak ada hubungan diantara kedua variabel yang diteliti dengan sikap ibu terhadap kekerasan pada anak. Hasil ini berbeda dengan penelitian Andayani (2002) yang menyebutkan bahwa nilai anak memiliki pengaruh secara tidak langsung terhadap perlakuan salah pada anak, selain itu tekanan ekonomi yang cukup berat menjadi rentan seseorang untuk bersikap emosional. ${ }^{11}$

Strategi yang dapat diterapkan dalam mencegah kekerasan pada anak yaitu dengan cara mengurangi faktor-faktor yang membuat keluarga rentan terhadap perilaku kekerasan dengan memperkuat keterampilan pengasuhan anak. Memberikan pengetahuan kepada orang tua dan pengasuh tentang interaksi orang tua dan anak yang positif termasuk penerapan disiplin anti kekerasan dalam pengasuhan anak. Strategi ini berupaya penuh dalam mendukung orang tua, pengasuh, dan keluarga dalam penyediaan informasi, pendidikan dan pengetahuan mengenai "parenting skill". Dengan tujuan mengurangi kejadian kekerasan dan tentunya orang tua dapat bersikap menolak menerapkan kekerasan dalam pola asuhnya. ${ }^{12}$

Namun demikian masih ada beberapa pandangan mengenai keyakinan orang tua bahwa anak pada dasarnya jahat. Beberapa tindakan kekerasan pada anak yang dilakukan oleh orang tua dengan keyakinan bahwa anak tidak dapat dipercaya karena mereka nakal sejak lahir. ${ }^{13}$ Sementara penelitian Putri (2012) menyebutkan bahwa kekerasan yang ditemui dalam penelitiannya dikarenakan karakter yang dimiliki orang tua. ${ }^{14}$

\section{SIMPULAN}

1. Sebagian besar dari responden dengan status ekonomi menengah kebawah sebanyak 69 orang $(94,5 \%)$, sebagian besar memiliki pandangan tidak keliru tentang posisi anak dalam keluarga yaitu sebanyak 39 orang $(53,4 \%)$ dan setengahnya memiliki sikap positif terhadap kekerasan pada anak sebanyak 35 orang $(47,9 \%)$.

2. Tidak ada hubungan status ekonomi keluarga dengan sikap ibu terhadap kekerasan pada anak di Kampung Cidahu Kecamatan Ngamprah Kabupaten Bandung Barat.

3. Tidak ada hubungan pandangan terhadap posisi anak dengan sikap ibu terhadap kekerasan pada anak di Kampung Cidahu Kecamatan Ngamprah Kabupaten Bandung Barat. 


\section{SARAN}

1. Bagi Bidan dan Puskesmas

Dapat Ditingkatkan komunikasi, edukasi dan informasi berkaitan dengan pencegahan kekerasan pada anak sebagai upaya membentuk perkembangan anak yang optimal.

2. Bagi Orang Tua

Diharapkan dapat meningkatkan pengetahuan mengenai pola asuh yang tepat diterapkan pada anak.

3. Bagi peneliti lain

Diharapkan dapat dilakukan penelitian lebih lanjut berkaitan dengan faktor-faktor yang lain yang menjadi pencetus kekerasan pada anak alam keluarga.

\section{DAFTAR PUSTAKA}

1. Soejiningsih. Tumbuh Kembang Anak dan remaja. Jakarta: EGC; 2006.

2. Aulina, C.N. Penanaman Disiplin Pada Usia Dini. Pedagogia. 2013 [diakses tanggal 10 April 2017]; 1(2): 36-49.

3. KPAI. Data Kasus Anak Pemantauan Media Online 2016. Diunduh dari : Http://bankdata.kpai.go.id/tabulasi-data/data-kasus-dari-media-online/data-kasus-anakpemantauan-media-online-2016.

4. Mutmainnah. Kekerasan Terhadap Anak. Bandung: Nuasa Press; 2014

5. Sugiyono. Metode Penelitian Eksperimen. Dalam: Metode penelitian kombinasi (Mixed Methode). Bandung: Alfabeta; 2011.

6. Sastroasmoro S. Dasar-dasar metodologi penelitian klinis. Jakarta: Sagung Seto; 2014.

7. Dahlan MS. Besar Sampel dan Cara Pengambilan Sampel. Jakarta: Salemba Medika; 2010.

8. Dahlan MS. Statistik Untuk Kedokteran dan Kesehatan. Jakarta: Salemba Medika;2011

9. Azwar. Sikap Manusia Teori dan Pengukurannya. Yogyakarta: Pustaka Belajar; 2015

10. Soekanto. Sosiologi Sebagai Pengantar. Jakarta: Rajagrafindo Persada; 2012

11. Andayani TR, Walgito B. Perlakuan Salah terhadap Anak (Child Abuse) ditinjau dari Nilai Anak dan Pendidikan Orangtua. Sosiohumanika. 2002. [Diakses tanggal 10 April 2017]; 15(3): 621-639

12. Hasanah U, Raharjo ST. Penanganan Kekerasan Anak Berbasis Masyarakat. Sosial Work Jurnal. 2016. [Diakses tanggal 10 April 2017]; 6 (1): 80-92.

13. Solihin L. Tindakan Kekerasan Pada Anak dalam Keluarga. Jurnal Pendidikan Penabur. 2004. [Diakses tanggal 12 April 2017]; 3(3): 129-139.

14. Putri AM, Santoso A. Persepsi Orang Tua Tentang Kekerasan Verbal Pada Anak. Jurnal Nursing Studies. 2012 [Diakses tanggal 10 April 2017]; 1(1); 22-29 